\title{
Effects of Additions of Noble Metals on the Properties of Antiferromagnetic Invar-Type Mn-Ge Alloys*
}

\author{
By Takafumi Nakayama**, Hakaru Masumoto** and Michio Kikuchi**
}

\begin{abstract}
The thermal expansion, magnetic properties, hardness and workability were investigated in Mn$22 \% \mathrm{Ge}$ based ternary $\varepsilon$ phase alloys containing noble metals in groups VIIA, VIII and IB of the periodic table. In the thermal expansion curves of the ternary alloys there appears a minimum corresponding to the Néel point of the $\varepsilon$ phase, showing the Invar characteristics below this temperature. The thermal expansion coefficient of the ternary alloys in the vicinity of room temperature shows the zero or a negative value. The spontaneous volume magnetostriction of $\mathrm{Mn}-22 \% \mathrm{Ge}-0.9 \% \mathrm{Ir},-1.7 \% \mathrm{Ag}$ and $-0.9 \% \mathrm{Au}$ alloys at $77 \mathrm{~K}$ is about $1.3 \times 10^{-2}$. The value is hardly affected by the additions and is nearly equal to those of a Mn-22\%Ge binary alloy and Invar-type $\mathrm{Fe}-\mathrm{Ni}$ or $\mathrm{Fe}-\mathrm{Pt}$ alloys. The magnetization of the ternary alloys shows almost the same temperature dependence as that of the Mn-22\%Ge binary alloy which shows a parasitic ferromagnetism. The magnetization at $T / T_{\mathrm{N}}=0.65$ decreases with increase of the additions except $\mathrm{Ag}$. The Néel point of the $\varepsilon$ phase is scarcely affected by the additions except $\mathrm{Ir}, \mathrm{Pt}$ and Re.

The Vickers hardness of almost all ternary alloys containing the noble metals less than $2 \%$ shows a value lower than that of $\mathrm{Mn}-\mathrm{Ge}$ alloys, and they are superior in workabilities such as cutting and forging to the binary alloys.
\end{abstract}

(Received September 7, 1985)

Keywords: Invar, thermal expansion, manganese-germanium based alloys, noble metals, hexagonal alloys, antiferromagnetism, magnetization, Néel point, hardness

\section{Introduction}

The appearance of the pronounced Invar characteristics of Mn-Ge alloys in the antiferromagnetic $\varepsilon$ phase region has been discovered and reported in detail by the present authors ${ }^{(1)(2)}$. Despite their excellent Invar characteristics, these alloys are in need of improvements in workability, particularly cold working, because the composition range of the binary alloys is close to the $\mathrm{Mn}_{3.25} \mathrm{Ge}$ compound $^{(3)}$. To improve these disadvantages, the effects of additions of third elements and various heat treatments were investigated. The results showed that the $\mathrm{Mn}-\mathrm{Ge}-\mathrm{Fe}$ ternary alloys $^{(4)}$ and several ternary alloys containing a

* This paper was presented at the 1982 Autumn Meeting of the Japan Institute of Metals. Reported originally in Japanese in J. Japan Inst. Metals, 49 (1985), 84; The 214th report from the Research Institute of Electric and Magnetic Alloys.

* The Research Institute of Electric and Magnetic Alloys, 2, Yagiyama-minami, Sendai 982, Japan. bcc metal such as $\mathrm{Zr}, \mathrm{V}$ or $\mathrm{Cr}^{(5)}$ had better workability than that of the binary alloys.

Generally, noble metals in groups VIII and IB of the periodic table have a fcc structure and excellent malleability and ductility. Furthermore, Mn and the noble metals are known to form compounds or alloys with various interesting characteristics ${ }^{(6)}$. For example, $\mathrm{Mn}_{2} \mathrm{Pd}_{3}$ is an antiferromagnetic compound showing the Invar characteristics ${ }^{(7)}$. In the present paper, investigations have been made on the effects of additions of noble metals and $\mathrm{Re}$ in group of VII A on the thermal expansion, magnetization, hardness and workability of the Invar-type Mn-Ge alloys.

\section{Experimental}

Starting materials used were $99.8 \%{ }^{\dagger}$ purity electrolytic Mn, 99.999\% purity metallic $\mathrm{Ge}^{(2)(4)(5)}$ and nine $99.8-99.9 \%$ purity noble

\footnotetext{
The alloy compositions except the purities of the elements are shown in units of atomic per cent.
} 
metals. These elements were weighed out and melted in alumina crucibles using a Tammann or an induction furnace while blowing $\mathrm{Ar}$ gas onto the melt surfaces. The molten alloys were sucked up into silica tubes about $3.0 \mathrm{~mm}$ in inner diameter. The specimens were cut to a length of about $100 \mathrm{~mm}$ for the thermal expansion measurement. For the workability test, the alloys were cast into iron molds $5 \mathrm{~mm}$ in inner diameter and $150 \mathrm{~mm}$ in length. All specimens were heated at about $1100 \mathrm{~K}$ $\left(830^{\circ} \mathrm{C}\right)$ for $10.8 \mathrm{ks}(3 \mathrm{~h})$ in silica tubes filled with $\mathrm{Ar}$ gas for homogenization and then allowed to cool in air to room temperature or quenched into water.

The linear thermal expansion was measured by a horizontal and a vertical type dilatometer at a rate of $27.8 \times 10^{-3} \mathrm{~K} / \mathrm{s}\left(100^{\circ} \mathrm{C} / \mathrm{h}\right)$ or less in the temperature range between 120 and $500 \mathrm{~K}$ in an $\mathrm{Ar}$ atmosphere. The magnetization measurement was carried out in an external magnetic field of about $800 \mathrm{kA} / \mathrm{m}(10 \mathrm{kOe})$ under the same condition as for the measurement of thermal expansion. The hardness was obtained at room temperature using a microVickers hardness tester under a load of $4.9 \mathrm{~N}$ (500 gf). The cutting and forging abilities were also tested by a bench lathe and a swaging hammer under the same conditions reported already $^{(4)(5)}$.

\section{Results and Discussion}

\section{Thermal expansion}

Figures 1(a)-(c) show the thermal expansion curves of $\mathrm{Mn}-22 \% \mathrm{Ge}$ base ternary alloys containing noble metals, which have the remarkable Invar characteristics measured over the temperature range from 120 to $500 \mathrm{~K}$ after heating at $1100 \mathrm{~K}$ for $10.8 \mathrm{ks}$ in $\mathrm{Ar}$ atmosphere, followed by air cooling. All the curves changed reversibly by heating and cooling at a rate less than $27.8 \times 10^{-3} \mathrm{~K} / \mathrm{s}$. In the figure, the arrow indicated to the minimum shows the Néel point $T_{\mathrm{N}}$ of the antiferromagnetic $\varepsilon$ phase. Almost all alloys have a small thermal expansion coefficient over a wide temperature range below $T_{\mathrm{N}}$ and show good Invar characteristics. When $\mathrm{Ru}, \mathrm{Rh}$ or $\mathrm{Pd}$ is added to the binary alloy, the Invar characteristics appears distinctly around 3.5\% or less (Fig. 1(a)). By addition of Ir or Pt, the anomaly in the thermal expansion curve disappears above $2 \%$ (Fig. 1(b)). The alloy added by $3.4 \% \mathrm{Ag}$ retains the Invar characteristics similar to that for the addition of $\mathrm{Ru}, \mathrm{Rh}$ or $\mathrm{Pd}$, while the Invar characteristics is weakened by the addition of about $2 \%$ of Au or Re (Fig. $1(c))$.

The spontaneous volume magnetostriction of $\mathrm{Mn}-22 \% \mathrm{Ge}-0.9 \% \mathrm{Ir},-1.7 \% \mathrm{Ag}$ and $-0.9 \%$ $\mathrm{Au}$ ternary alloys was about $1.2-1.3 \times 10^{-2}$, which was calculated from the difference in the thermal expansion between the alloys mentioned above and other Mn-Ge alloys showing no anomaly in the thermal expansion. The value is of the same order of magnitude as that of the binary alloy and ferromagnetic $\mathrm{Fe}-\mathrm{Ni}^{(8)}$ and $\mathrm{Fe}-\mathrm{Pt}^{(9)}$ Invar alloys.

The Invar characteristics of the $\mathrm{Mn}-\mathrm{Ge}$ alloys are retained fairly well up to $2 \%$ of the noble metals as mentioned above. To make clear the effects of the noble metals, the thermal expansion coefficient $\alpha_{\mathrm{RT}}$ at temperatures between 270 and $310 \mathrm{~K}$ was measured for each alloy. Figure 2 shows the variation of $\alpha_{\mathrm{RT}}$ with the concentration of the third elements. In the figure, the curves are classified into 3 groups; $\mathrm{Ru}, \mathrm{Rh}$ and $\mathrm{Pd}$ of the fifth period, In, Pt and Os of the sixth period in group VIII of the periodic table, and $\mathrm{Ag}, \mathrm{Au}$ and $\mathrm{Re}$ group. Although the expansivity of the alloys containing $\mathrm{Ru}, \mathrm{Rh}$ or $\mathrm{Pd}$ shows a quite small value in the concentration range less than $3 \%$, the alloys with $\mathrm{Ir}, \mathrm{Pt}$ and Os additions shows a minimum at $1 \%$ or less and then increases with increasing concentration of additional element. The addition of Au or Re brings about a large effect as in the case of the alloy with the sixth period element Ir, Pt or Os in group VIII, while the alloys with the addition of $\mathrm{Ag}$ shows a small value of $\alpha_{\mathrm{RT}}$ even at $3.4 \%$. From the results mentioned above, it becomes clear that the narrow composition range in the binary alloy in which the Invar characteristics appear is expanded by the addition of noble metals in a way similar to the $\mathrm{Mn}-\mathrm{Ge}$ alloys containing $\mathrm{Fe}^{(4)}$ or $\mathrm{Cr}^{(5)}$. 

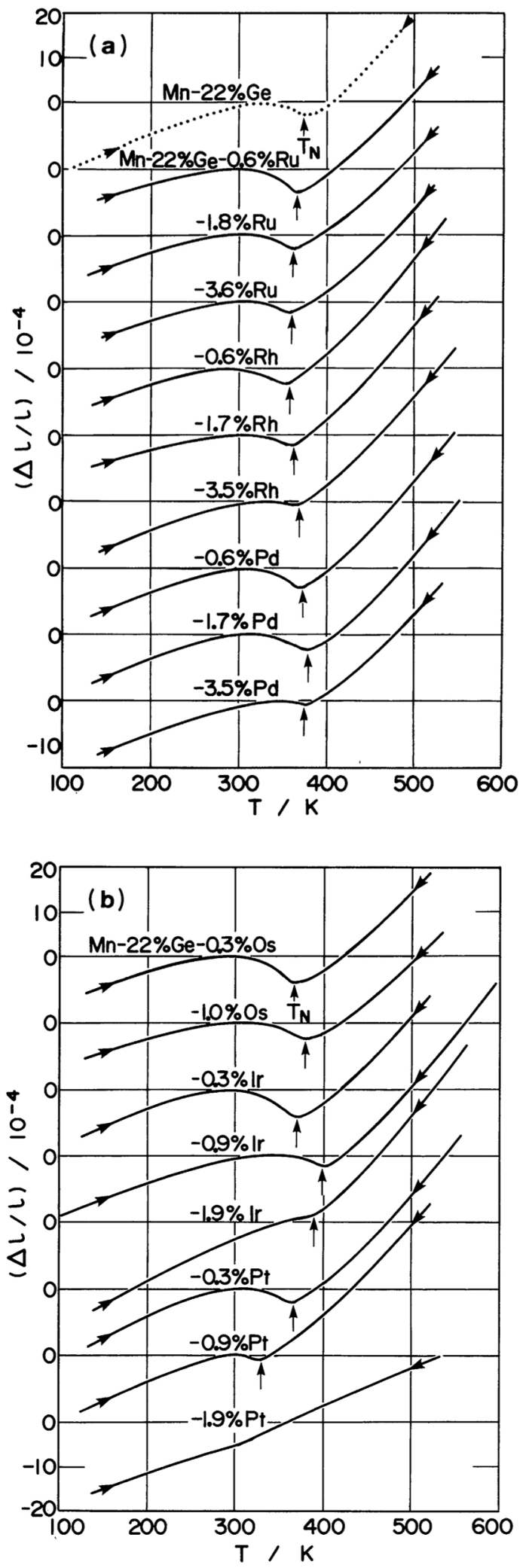

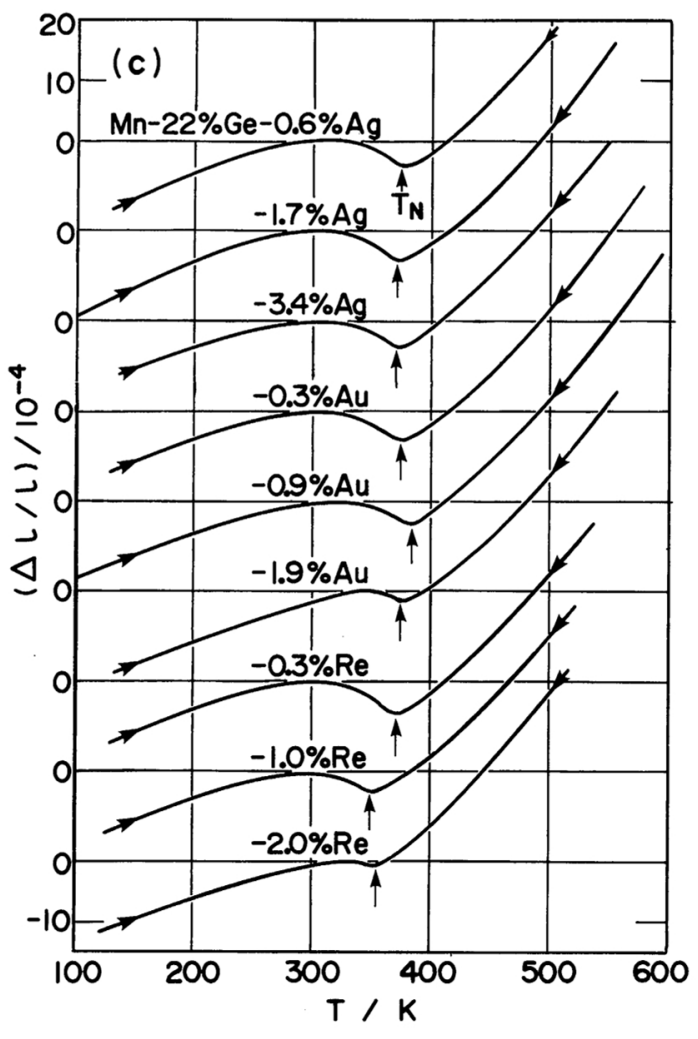

Fig. 1 (a) Thermal expansion curves of $\mathrm{Mn}-22 \% \mathrm{Ge}$ alloys containing $\mathrm{Ru}, \mathrm{Rh}$ or $\mathrm{Pd}$. (b) Thermal expansion curves of $\mathrm{Mn}-\mathbf{2 2} \% \mathrm{Ge}$ alloys containing Os, Ir or Pt. (c) Thermal expansion curves of Mn-22\% Ge alloys containing $\mathrm{Ag}, \mathrm{Au}$ or $\mathrm{Re}$. 


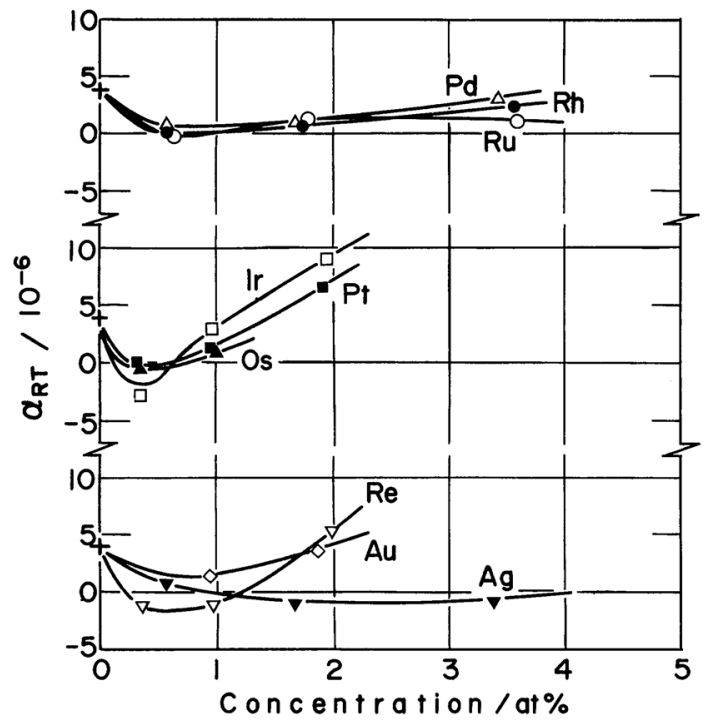

Fig. 2 Effects of noble metals on the thermal expansion coefficient in the vicinity of room temperature in $\mathrm{Mn}-$ $22 \%$ Ge alloy.

\section{Magnetization}

Figures 3(a) and (b) show the relation between temperature and magnetization $\sigma$ of the typical ternary alloys air-quenched after heating at $1100 \mathrm{~K}$ for $10.8 \mathrm{ks}$. The measurements were carried out by heating and cooling at a rate of about $27.8 \times 10^{-3} \mathrm{~K} / \mathrm{s}$. The $\sigma-T$ curves in (a) are similar in shape, although $T_{\mathrm{N}}$ slightly shifts upwards or downwards by addition of the third element. The variation in the temperature dependence of magnetization with $\mathrm{Ag}$ concentration is shown in (b), in which $T_{\mathrm{N}}$ hardly changes with increasing Ag concentration, the magnetization at low temperature increases slightly and steep change in $\sigma$ is observed just below $T_{\mathrm{N}}$. In particular, these alloys have a relatively large magnetization and exhibit a ferromagnetic temperature variation due to the existence of weak ferromagnetism ${ }^{(10)}$ in the antiferromagnetic $\varepsilon$ phase. It has been reported that the spin structure of $\mathrm{Mn}_{3.25} \mathrm{Ge}$ intermetallic compound is a $\mathrm{D}_{19}$ type $^{(11)(12)}$.

In order to confirm the phase structures of the ternary alloys, diffraction patterns of powdered samples were measured by $\mathrm{FeK}_{\alpha} \mathrm{X}$ rays. The result showed that in the alloys with about $3.5 \%$ of $\mathrm{Ru}, \mathrm{Rh}, \mathrm{Pd}$ or $\mathrm{Ag}$ there was
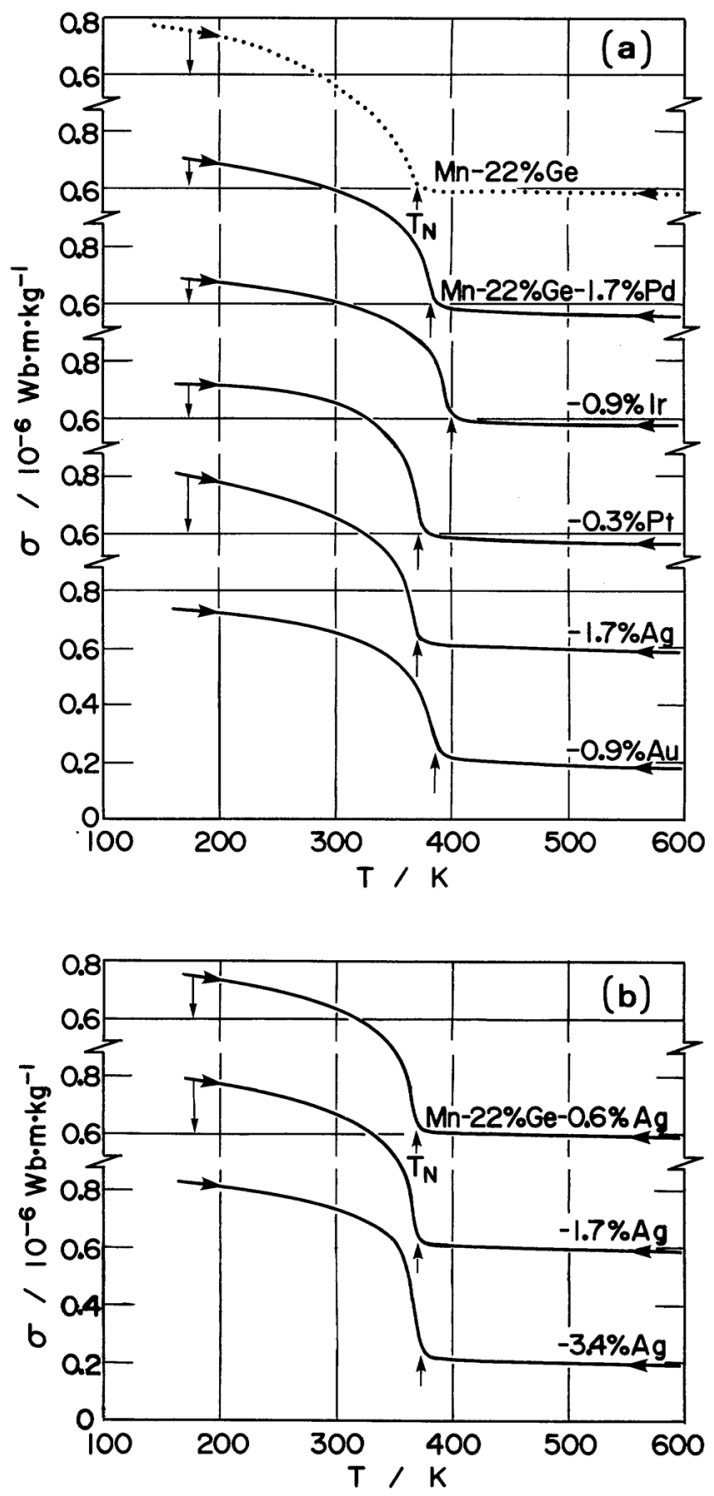

Fig. 3 (a) Temperature dependence of magnetization of Mn-22\%Ge-X alloys. (b) Temperature dependence of magnetization of $\mathrm{Mn}-22 \% \mathrm{Ge}-\mathrm{Ag}$ alloys.

a small amount of the antiferromagnetic $\zeta$ phase mixed with the $\varepsilon$ phase and the amount of the $\zeta$ phase increased in the order of $\mathrm{Ag}, \mathrm{Ru}$, $\mathrm{Rh}$ and $\mathrm{Pd}$. In the alloys containing $\mathrm{Ir}$ or $\mathrm{Pt}$, the $\zeta$ phase pattern began to appear above $1.9 \%$.

In order to examine the relation between the magnetization and the concentration of the third elements, the magnetization $\sigma_{\mathrm{T}}$ at 


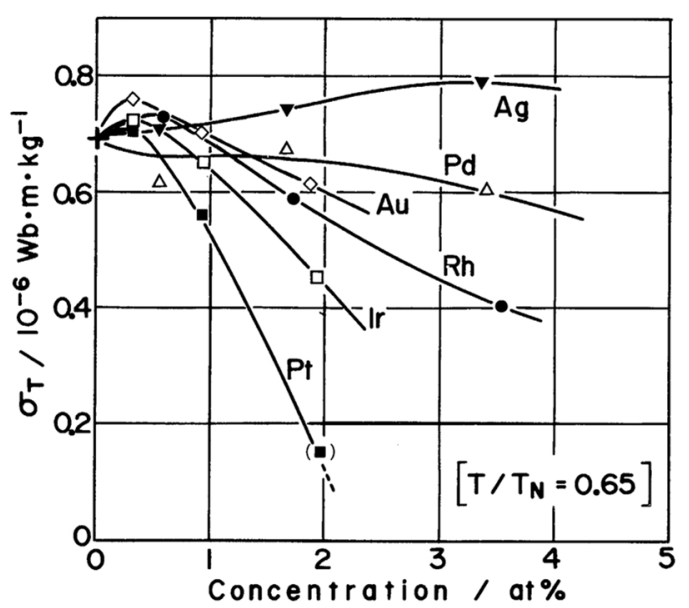

Fig. 4 Effects of noble metals on the magnetization of $\mathrm{Mn}-22 \% \mathrm{Ge}$ alloy at the temperature $T / T_{\mathrm{N}}=0.65$.

temperature $T$ where $T / T_{\mathrm{N}}=0.65$ is shown in Fig. 4 as an example. In general, the $\sigma_{\mathrm{T}}$ decreases linearly with increasing concentration of the third element. However, the value in the case of the $\mathrm{Ag}$ addition tends to increase up to about $3 \%$.

Figure 5 shows the effects of the addition of the third elements on $T_{\mathrm{N}}$ of the $\mathrm{Mn}-22 \% \mathrm{Ge}$ binary alloy. The effects of $\mathrm{Ru}, \mathrm{Rh}, \mathrm{Pd}$ or $\mathrm{Ag}$ of the fifth period in groups VIII and IB of the periodic table are small, while those of Os, Ir or Pt of the sixth period in group VIII are large. The addition of $\mathrm{Pd}, \mathrm{Ir}$ or $\mathrm{Au}$ increases $T_{\mathrm{N}}$, and thereby the Invar characteristics appear over a wider temperature range. Furthermore, the alloys with $1-2 \% \mathrm{Pd}$ or $\mathrm{Au}$ show an excellent cutting ability by a bench lathe. Therefore, it seems that the Invar type $\mathrm{Mn}-\mathrm{Ge}$ alloys containing a small amount of the noble metals are very promising materials for practical use in a similar way to the alloys containing $\mathrm{Fe}^{(4)}$ or $\mathrm{Cr}^{(5)}$.

There have been a number of investigations on various physical properties of the Mn-noble metals alloys. Yamaoka ${ }^{(13)}$ reported a drastic increase of $T_{\mathrm{N}}$ as large as $9 \mathrm{~K} / \mathrm{at} \% \mathrm{Ir}$ in the $\gamma$ phase Mn-Ir alloys containing Ir less than $15 \%$. In the present work, it is apparent from Fig. 5 that only $1 \%$ Ir gives rise to a marked increase in $T_{\mathrm{N}}$ of about $15 \mathrm{~K}$, and the phenomenon is considered in a way similar to the $\mathrm{Mn}-\mathrm{Ir}$ alloys.

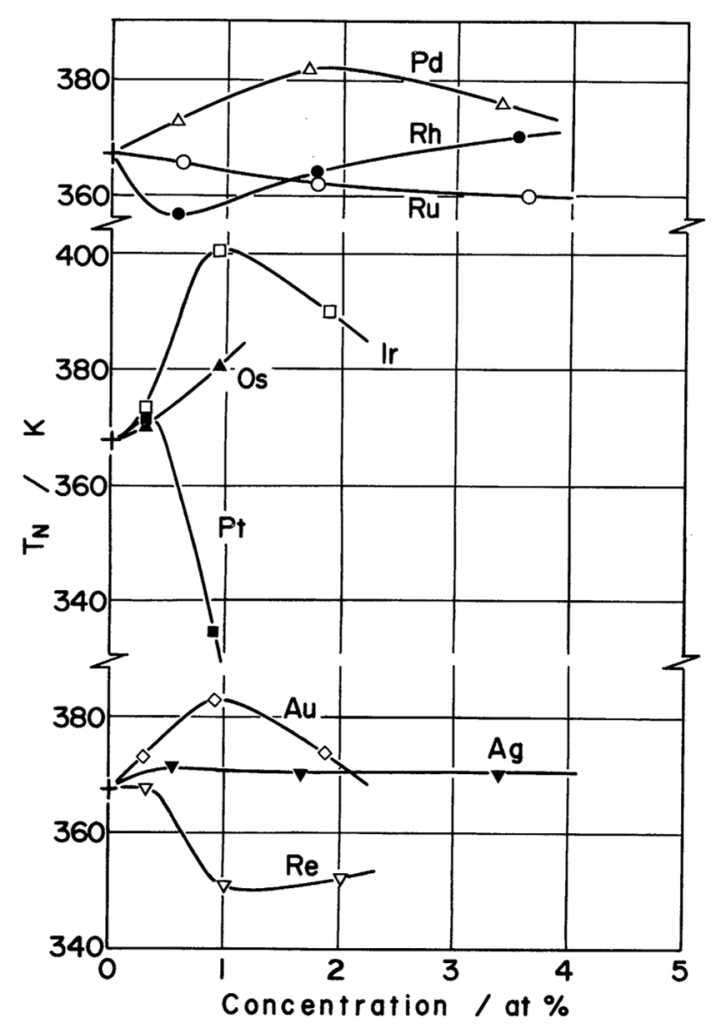

Fig. 5 Effects of noble metals on the Néel point of Mn$22 \%$ Ge alloy.

Vickers hardness $H_{\mathrm{V}}$ was measured in the $\mathrm{Mn}-22 \% \mathrm{Ge}$ base alloys containing a few per cent of the noble metals under a load of $4.9 \mathrm{~N}$ (500 gf) at room temperature, as shown in Fig. 6. The alloy with $2 \%$ Ir tends to develop a higher $H_{\mathrm{V}}$ by about 50 as compared with the binary alloy. The addition of other elements except Ir lowers the $H_{\mathrm{v}}$; particularly the addition

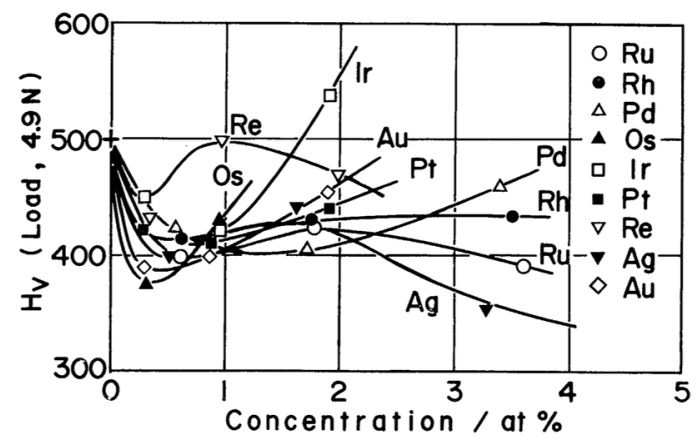

Fig. 6 Effects of noble metals on the room-temperature Vickers hardness of $\mathrm{Mn}-22 \% \mathrm{Ge}$ alloy. 
of $\mathrm{Pd}, \mathrm{Pt}$ and $\mathrm{Au}$ lowers the value by only $1 \%$ addition to the same order of magnitude as that by the addition of $\mathrm{Fe}^{(4)}$, and the addition of $\mathrm{Ru}$ and $\mathrm{Ag}$ decreases it to a value of 400 or less.

The forgeability test for the $\phi 5 \mathrm{~mm}$ rod alloys with 1-2\% noble metals was carried out by a swaging hammer at room temperature. Except in the alloys with Os, Ir or Re, the workability of about $5 \%$ in the reduction area was possible in the other alloys. From the turning tests made by a bench lathe in the same condition as used in previous works ${ }^{(4)(5)}$, it has been found that the alloys with Pd or Au have a good workability, while those with Os, Ir or $\mathrm{Re}$ are difficult of cutting. The former two alloys show better workability than the binary alloy, and this is a tendency similar to the alloys containing $\mathrm{Fe}^{(4)}$ or $\mathrm{Cr}^{(5)}$.

From the results mentioned above, it is apparent that the antiferromagnetic $\varepsilon$-phase MnGe alloys containing 3\% or less noble metals show the excellent Invar characteristics and good workability. So, these alloys are suitable for precision measuring instruments such as the optical system in which the microscopic dimensional change by heating and/or application of magnetic fields should be avoided.

\section{Summary}

The Mn-22\%Ge Invar alloy has been used as the base alloy for the investigation of the effect of small additions of the noble metals of the fifth and sixth periods in groups VIII and IB of the periodic table. Measurements of the magnetization, the thermal expansion, the hardness and the workability (mainly cutting ability) were performed on the ternary alloys air-quenched or water-quenched after heating at $1100 \mathrm{~K}$ for $10.8 \mathrm{ks}$. The results are summarized as follows:

(1) In the thermal expansion vs temperature curves of the $\mathrm{Mn}-22 \% \mathrm{Ge}$ based ternary alloys, there exists a bend or a minimum at the Néel point of the antiferromagnetic $\varepsilon$ phase. Most alloys have a small thermal expansion coefficient and show the Invar characteristics below the Néel point.

(2) The thermal expansion coefficient in the vicinity of room temperature takes the zero or a small negative value by the addition of some of the noble metals, and the Invar characteristics are obtained over a wide composition range.

(3) The spontaneous volume magnetostriction of the $\mathrm{Mn}-22 \% \mathrm{Ge}-0.9 \% \mathrm{Ir},-1.7 \% \mathrm{Ag}$ and $-0.9 \% \mathrm{Au}$ alloys at $77 \mathrm{~K}$ is $1.2-1.3 \times 10^{-2}$, and this is nearly the same value as those of the binary alloy and ferromagnetic $\mathrm{Fe}-\mathrm{Ni}$ and $\mathrm{Fe}-$ Pt Invar alloys.

(4) In the antiferromagnetic $\mathrm{Mn}-22 \% \mathrm{Ge}$ base ternary alloys, the variation in the temperature dependence of magnetization is similar to that of the ferromagnetic alloys because of the existence of weak ferromagnetism.

(5) The magnetization of the $\mathrm{Mn}-22 \% \mathrm{Ge}$ base ternary alloys at the temperature of $T /$ $T_{\mathrm{N}}=0.65$ decreases with addition of third element, but the value increases in the case of addition of about $3 \% \mathrm{Ag}$.

(6) The Néel point in the alloys with Pd, Ir or Au shows values higher than in the binary alloy, but that in the alloys with $\mathrm{Ru}, \mathrm{Rh}$ or $\mathrm{Ag}$ shows values little affected by the addition.

(7) In comparison with the binary alloy, the Vickers hardness of the ternary alloys containing $2 \%$ or less noble metals shows a lower value, except for the addition of Ir. The ternary alloys containing the noble metals except Os, Ir and Re have forgeability of about $5 \%$ reduction rate in the sectional area and show improvements in the cutting ability by a bench lathe.

\section{REFERENCES}

(1) H. Masumoto, M. Kikuchi and T. Nakayama: J. Japan Inst. Metals, 45 (1981), 107 (in Japanese).

(2) H. Masumoto, M. Kikuchi and T. Nakayama: Trans. JIM, 24 (1983), 42.

(3) T. Ohoyama: J. Phys. Soc. Japan, 16 (1961), 1995.

(4) H. Masumoto, M. Kikuchi and T. Nakayama: Trans. JIM, 24 (1983), 773.

(5) H. Masumoto, T. Nakayama and M. Kikuchi: Trans. JIM, 25 (1984), 828.

(6) S. Chikazumi, K. Oota, K. Adachi, N. Tsuya and Y. Ishikawa: Jiseitai-Hando-bukku, Asakura-shoten, Tokyo (1975), p. 371.

(7) H. Saito and K. Fukamichi: Trans. JIM, 12 (1971), 68.

(8) G. Hausch: Phys. Status Solidi, (a)18 (1973), 735. 
(9) K. Sumiyama, M. Shiga and Y. Nakamura: J. Magn. Magn. Mat., 12 (1979), 1.

(10) S. Tomiyoshi: J. Phys. Soc. Japan, 51 (1982), 803.

(11) S. Tomiyoshi and Y. Yamaguchi: J. Phys. Soc.
Japan, 51 (1982), 2478.

(12) G. Kádár and E. Krěn: Intern. J. Magnetism, 1 (1971), 143.

(13) T. Yamaoka: J. Phys. Soc. Japan, 36 (1974), 445. 